\title{
A não pouca ambição
}

\section{Constança Carvalho Homem}

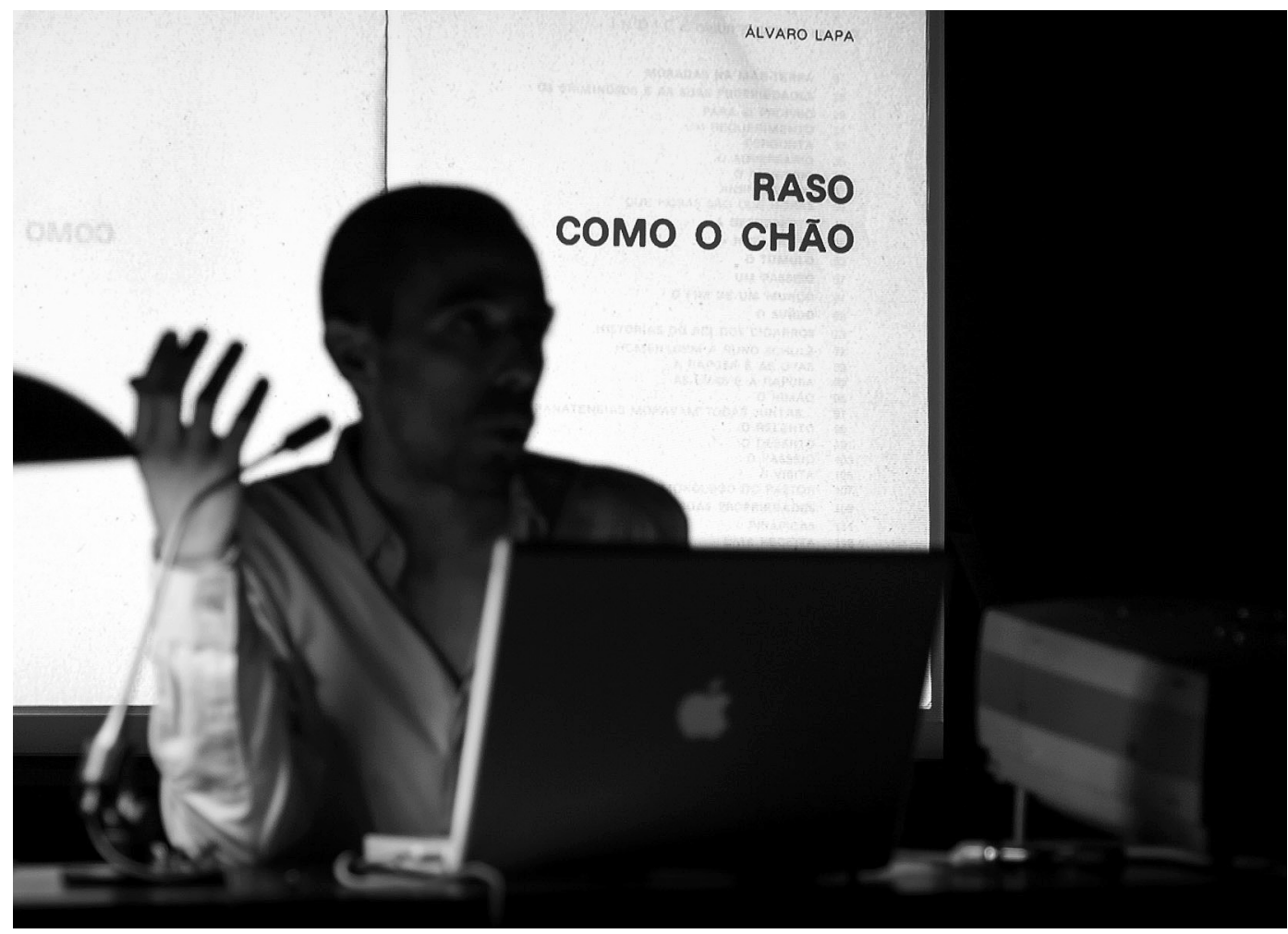

Raso como o chão,

de João Sousa Cardoso

e Ana Deus, TeCA, 2012 (João Sousa Cardoso),

fot. João Tuna.

Titulo: Raso como o chão. Autor: Ana Deus e João Sousa Cardoso, a partir de Álvaro Lapa. Interpretação:Ana Deus e João Sousa Cardoso. Produção: Três Quatro Lente. Local e data de estreia:TeCA, Porto, 15 de Setembro de 2012.

Escrevo sobre Raso como o chão conservando a memória da sua última apresentação pública, no Teatro Viriato, em Viseu, a 9 de Março de 2013. Ou, com absoluta franqueza, somando essa memória ao bloqueio em que me vi após a estreia do espectáculo no TeCA, em Setembro último.

Possivelmente sob influência de uma plateia pouco reactiva, preferi não falar durante algum tempo desse lugar aonde fora, que, sendo de frustração, também era de saciedade. Concluí o que semanas mais tarde viria a formular: que onde Raso como o chão parece não ser espectáculo é que encontra a sua força. Sem auto-proclamação e sem entusiasmo paródico, que podem ser as mais evidentes bandeiras, foi-me dificil reconhecer, enquadrar, este lote fecundo do território pós-dramático. Sendo certo que isto sublinha uma inexperiência crítica, dirá também qualquer coisa sobre o tecido criativo circundante, que tarda a renovar-se, maioritariamente, ou intenta uma contemporaneidade equivoca, não raro assente em relações enfermas entre continente e conteúdo. Neste caso, falarei de inteligência e discrição, que são virtude tanto como a chave da blindagem deste espectáculo.

A premissa é claramente enunciada, "ler, analisar e partilhar convosco" uma obra literária, e em tudo servida por um guião e dispositivo afinizados com a conferência 


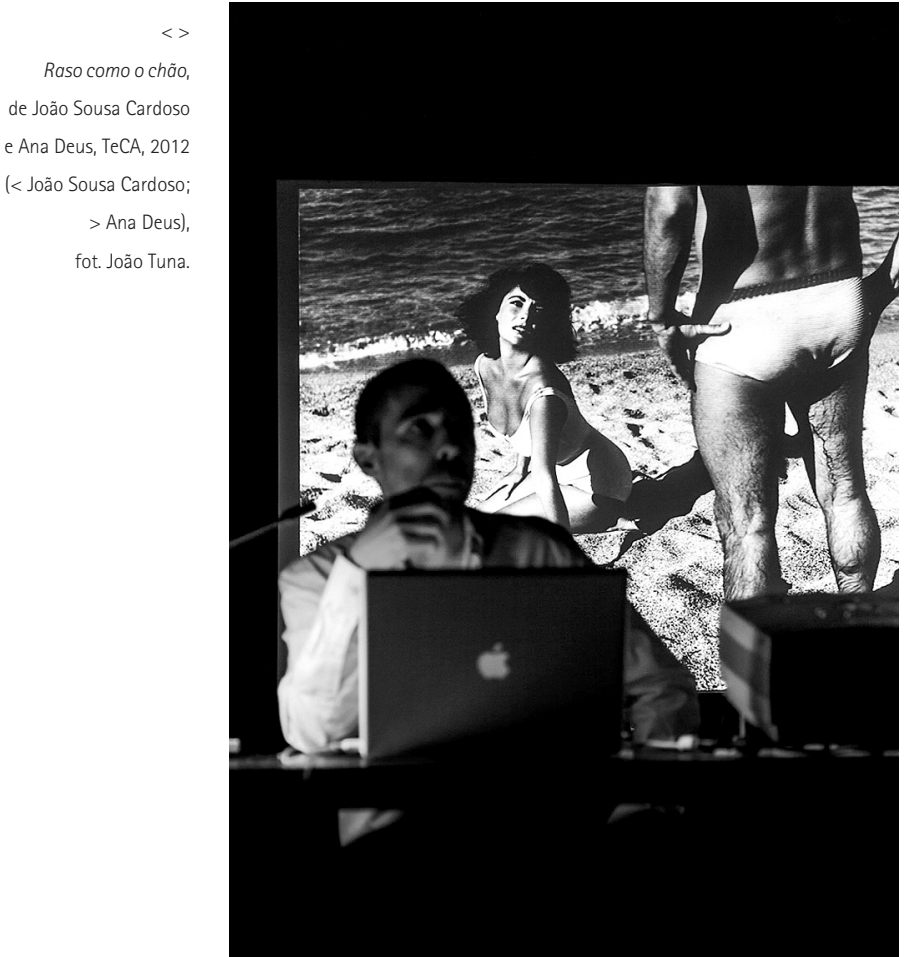

- há uma mesa de trabalho, um computador, um candeeiro a imagem projectada. A não pouca ambição começa na concepção holista da obra de Álvaro Lapa, segundo a qua a sua criação literária e pictórica seriam separadas por uma "esquizofrenia da recepção". A própria natureza avulsa (recolectora?) dos trinta e dois capitulos de Raso como o chão, em variação e tom por vezes próximos dos Novos contos do gin, de Mário-Henrique Leiria, pode ter desaconselhado uma aproximação purista. Mais, não parece tratar-se apenas de um livro inclassificável, o que explicaria em parte o seu insucesso comercial: o que é apresentado é "um texto sobre o problema das formas", "contra a tradição, pela tábua rasa". E é porventura nessa aversão ao categórico e ao categorial que os dois intérpretes encontram licença para o designado "crime de apropriação": eles arriscam pulverizar as metáforas de Lapa com as técnicas que o próprio parece ter cultivado, justapondo-as com desenvoltura e ironia. No entanto, a respiração do espectáculo depende de uma economia de signos e alusões dialogantes. Em cena, há também a escada, como a que vemos numa fotografia do estúdio onde foi criado o espectáculo, na Holanda: um cesto de laranjas pousado na mesa, a piscar o olho às mencionadas naturezas-mortas de Cézanne; um guarda-sol, a completar um aparente estudo de cor, ao mesmo tempo que metáfora activa desse umbigo do texto que são "os países do sul".

0 desafio de um espectáculo que quer ser mapa inscreve-se, julgo, no seu próprio decurso. 0 compasso é o da ponderação, quando não mesmo deambulatório, no que se acredita ter correspondência com a figura entrevista de Álvaro Lapa, professor, e com o seu recordado discorrer de "anti-pedagogo". Ousando a leitura, o comentário, a reminiscência, a enumeração, o facto biográfico (e só muito raramente um "imaginem!"); convocando Josefa de Óbidos, Bruno Schulz ou Paulo Rocha, reciclagem e priapismo, João Sousa Cardoso demonstra aqui que ao aluno de Lapa Ihe ficou esse vício de pôr em relação. 0

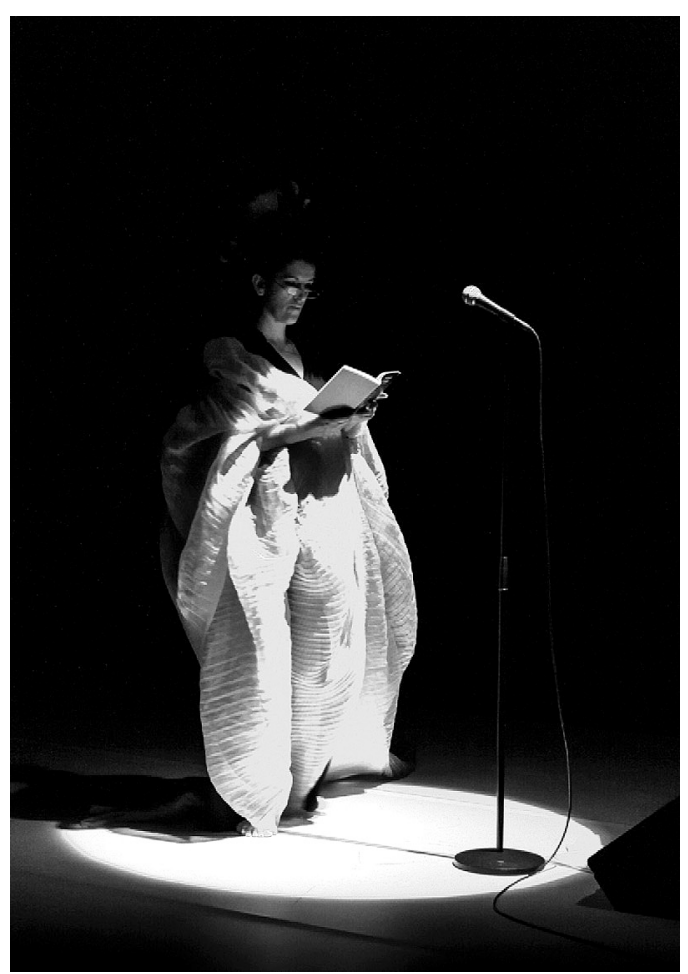

interesse desta estratégia é, porventura, o que a afasta do fruível mais óbvio: o objecto reclama do espectador a condição de instruendo, ao mesmo tempo que propõe uma instrução por densa acumulação, e desvio, nunca pelo nexo fácil. Sendo recursivo, procurando a planura, o desenvolvimento não-climático, o espectador é também confrontado com uma artificiosa contenção que the nega a ênfase e o recorte que ainda espera, senão já do actor, do palestrante. A este respeito, é obrigatório dizer que aquela que senti como principal incongruência foi reparada. No primeiro espectáculo, Ana Deus era ainda uma aparição manifestamente teatral, com figurino, perimetro de luz e registo em absoluto contraste com a palestra, coordenadas de certo apaziguamento porquanto compõem essa outra coisa admissivel num palco; em Viseu, prescindiu da caracterização e aproximou-se do piano em que João Sousa Cardoso se move, numa interpretação tão poderosa quanto singela. Se primeiro me ressenti de uma certa tendência ilustrativa, ouvindo a canção de intervenção e a Ana Deus no seu avatar cantautoral, de uma segunda vez ouvi sobretudo o texto - escrito por Lapa em 1977, vivido intensa e inesperadamente em 2013 - em encontro, em protesto. A fechar, uma canção de Regina Guimarães, ou de como o autor veio a viver nas palavras de alguns outros: "aquilo que cai ao chão é nosso", tão límpido.

Oportuno sem ser oportunista, como podia acontecer pela via da homenagem ou da demarcação, Raso como o chão é um espectáculo contra o seu tempo - tópico, brando, rarefeito, lento, e nessa ontologia um exercício de decência para com os tempos que vivemos. Antiquado, poderão dizer, convoluto também. A mim pareceu-me outra vez novo ousar fazer uno. A sua digressão, sendo quase milagre, dá saudável testemunho da vitalidade das casas que o acolheram. Outras houvesse em que mais gente pudesse vê-lo e repetir, com Lapa, um "eu não páro de educar-me, a educação é gratuita". Justamente por não ser. 